\title{
Molecular and Genetic Basis of Inherited Nephrotic Syndrome
}

\author{
Maddalena Gigante, ${ }^{1}$ Matteo Piemontese, ${ }^{2}$ Loreto Gesualdo, ${ }^{1}$ Achille Iolascon, ${ }^{3}$ \\ and Filippo Aucella ${ }^{2}$ \\ ${ }^{1}$ Division of Nephrology, Department of Biomedical Science, University of Foggia, 71121 Foggia, Italy \\ ${ }^{2}$ Nephrology and Dialysis Unit, Department of Medical Science, Research Institute, Casa Sollievo della Sofferenza Hospital, Viale \\ Cappuccini n. 1, San Giovanni Rotondo, 71013 Foggia, Italy \\ ${ }^{3}$ Department of Biochemistry and Medical Biotechnology, University of Naples Federico II and CEINGE- Advanced Biotechnologies, \\ 80127 Naples, Italy
}

Correspondence should be addressed to Filippo Aucella, faucel1@alice.it

Received 21 February 2011; Revised 16 June 2011; Accepted 16 June 2011

Academic Editor: Michel Fischbach

Copyright (C) 2011 Maddalena Gigante et al. This is an open access article distributed under the Creative Commons Attribution License, which permits unrestricted use, distribution, and reproduction in any medium, provided the original work is properly cited.

\begin{abstract}
Nephrotic syndrome is an heterogeneous disease characterized by increased permeability of the glomerular filtration barrier for macromolecules. Podocytes, the visceral epithelial cells of glomerulus, play critical role in ultrafiltration of plasma and are involved in a wide number of inherited and acquired glomerular diseases. The identification of mutations in nephrin and other podocyte genes as causes of genetic forms of nephrotic syndrome has revealed new important aspects of the pathogenesis of proteinuric kidney diseases and expanded our knowledge of the glomerular biology. Moreover, a novel concept of a highly dynamic slit diaphragm proteins is emerging. The most significant discoveries in our understanding of the structure and function of the glomerular filtration barrier are reviewed in this paper.
\end{abstract}

\section{Introduction}

The ultrafiltration of plasma during primary urine formation is one of the central function of the human kidney. Normal filtration function of the glomerulus depends on the structural and functional integrity of the filtration barrier, that is the primary target of several inherited and acquired glomerular disorders, characterized by nephrotic syndrome ( $>3.5 \mathrm{~g}$ protein/day) and rapid progression to end-stage renal disease (ESRD).

The glomerular filtration barrier, responsible for the size and charge-selective properties of renal filter, is composed of three separate layers: the fenestrated endothelium, the glomerular basement membrane (GBM), and the podocyte foot processes layer. Recent studies have emphasized the role of podocytes as a key cell type involved in the mechanisms responsible for proteinuria and glomerular damage [1-3]. Podocytes are injured in many forms of human and experimental glomerular diseases, including congenital nephrotic syndromes, minimal change disease (MCD), focal segmental glomerulosclerosis (FSGS), membranous glomerulopathy, diabetes mellitus, and lupus nephritis $[1,3,4]$. In fact, the majority of glomerular diseases are characterized by alterations in the molecular composition of the slit diaphragm (SD) and a reorganization of foot process structure with fusion and effacement. The major causes leading to foot process effacement and proteinuria are (i) abnormalities in the GBM or podocytes-GBM interactions; (ii) impaired formation of the slit diaphragm area; (iii) alterations of the actin cytoskeleton and associated proteins $[1,5-7]$.

A better understanding of the molecular properties of GBM, podocytes and the slit diaphragm is critical to develop novel therapeutic strategies for patients with glomerular disease and to prevent end-stage renal insufficiency.

Mutations in different podocyte proteins can target the function of the podocyte through distinct pathologic mechanism by affecting the structure of the slit diaphragm, by directly or indirectly perturbing the intricate podocyte 
cytoskeleton, by breaking cell-matrix interactions, or by blocking important signaling pathways. All these mechanisms result in a common final disease pathway characterized by podocyte foot processes effacement, proteinuria, and ultimately disruption of the glomerular filter (Figure 1).

The most significant discoveries in our understanding of the structure and function of the glomerular filtration barrier and related diseases are summarized in this paper.

\section{Podocyte Structure and Development}

Glomerular podocytes are highly differentiated cells with a complex cytoarchitecture. They have a voluminous cell body, long primary processes and regularly spaced, interdigitated foot processes that completely enwrap the glomerular capillaries (Figure 1). The interdigitated foot processes of neighboring podocytes cover the GBM and form a narrow filtration slit connected by an electron dense structure, called the slit diaphragm (SD), a zipper-like structure with a $40 \mathrm{~nm}$ diameter, according to the model proposed by Karnovsky and Ainsworth [8]. Podocytes are polarized epithelial cells with a luminal or apical and a basal cell membrane domain. A well-developed cytoskeleton accounts for the unique shape of the cells and the maintenance of the processes. The apical membrane of foot processes is equipped with a negatively charged surface coat, primarily made up of podocalyxin. This protein is critical for formation and preservation of cellular architecture: its absence causes immature glomeruli with flattened podocytes. The first marker of podocyte development in vertebrates is the restriction of WT1 expression to a subset of cells within the renal vesicle $[9,10]$. Several other transcription factors are expressed in the early podocytes, including podocyte-expressed 1 [11], forkhead box C2 (Foxc2) [12], kreisler (Mafb) [13], the forkhead domain transcription factor $M f 2$ [14], and the Lim domain protein $\operatorname{Lm} x 1 b$ [15].

WT1 is probably the best studied of the transcription factors expressed in podocytes. WT1 encodes a protein with four zinc fingers that can bind to both DNA and RNA $[16,17]$. In the fetal kidney, WT1 is expressed in metanephric mesenchyme, renal vesicles, and developing podocytes. In adult life, the WT1 expression is restricted to podocytes. In maturing glomeruli, WT1 expression increases while the PAX2 expression is downregulated. The homeobox PAX2 gene encodes for a transcription factor expressed early during development and essential for conversion of metanephric blastema to renal vescicole. Downregulation of PAX2 appears as a prerequisite to allow podocyte differentiation which is governed by WT1. Both WT1 and PAX2 knockout mice lack kidneys, suggesting the critical role of these transcription factors in metanephric development. Mutations in PAX2 gene are associated with renal coloboma syndrome and isolated renal hypoplasia. The WT1 expression is altered in both congenital and acquired human diseases. In particular, the WT1 expression is lost in podocytes of collapsed glomeruli. Dominant mutations in WT1 are associated with the DenysDrash and Frasier syndromes, characterized by glomerulopathy, mesangial sclerosis, male pseudohermaphroditism, and nephroblastoma. In these patients, the WT1 abnormal expression is associated with increased expression of PAX2 $[18,19]$.

POD1 (also known as epicardin and capsulin) encodes a basic helix-loop-helix transcription factor that is expressed early in mouse kidney development, and subsequently in the primitive podocytes of S-shaped bodies [20, 21]. Kreisler (MAFB) encodes a basic domain leucine zipper (bZip) transcription factor of the MAF subfamily and is expressed in mouse podocytes of capillary loop-stage glomeruli [22]. It also has an important role in hindbrain segmentation. Pod1 and kreisler mutations in mice result in similar phenotypes: glomerular development is arrested at the single capillary loop stage $[20,22]$, and the podocytes remain as columnarshaped cells that have lost their lateral cell-cell attachments but remain fully adhered to the GBM without any foot processes. Thus, Pod1 and kreisler are required just prior to the time when podocytes would normally begin migrating around the capillary loops and assembling foot processes. Pod1 is expressed in kreisler mutant podocytes, indicating that kreisler is likely to act either downstream or in a separate pathway from Pod1 [22].

Foxc2 was identified during a screen for genes with enriched expression in mouse glomeruli [12]. It belongs to the forkhead domain family of putative transcription factors and is expressed in podocytes. In Foxc2 mutant mouse kidneys, mesangial cells cluster at the base of the glomerular stalk, podocyte foot processes, and endothelial fenestrations are absent, and dilated capillaries are observed, similar to the other phenotypes discussed above [12].

LMX1B, a Lim homeobox gene, is another important transcription factor, regulating the expression of multiple genes which are critical for podocyte differentiation and function. Homozygous Lmx-1b knockout mice have reduced numbers of podocyte foot processes, absence of typical slit diaphragms, and glomerular basement membrane abnormalities, but they express near-normal levels of nephrin, synaptopodin, ZO-1, and GBM laminins. Mutations of the human Lmx-1b gene are responsible for the nail-patella syndrome, an autosomal dominant disease with skeletal abnormalities, frequently associated with glomerulopathy [24].

\section{Podocyte-GBM Interactions}

Proteinuria, the most common clinical manifestation of glomerular diseases, is invariably associated with podocyte foot process effacement, flattening, and retraction. To maintain the complex foot process architecture, the adhesion of the podocytes to the GBM is controlled by the expression of several adhesion proteins. The foot processes are fixed to the GBM via $\alpha_{3} \beta_{1}$-integrin and dystroglycan (DG) complex. The $\alpha_{3} \beta_{1}$-integrin binds to fibronectin, collagen IV, and laminin of GBM, and it is essential for maturation of podocytes, as shown by the loss of foot processes development in $\alpha_{3}$ deficient mice. The dystroglycan complex is connected to podocyte actin cytoskeleton (Figure 1) through urotrophin, and its expression is reduced in MCD but not in membranous nephritis and FSGS [25-27]. 


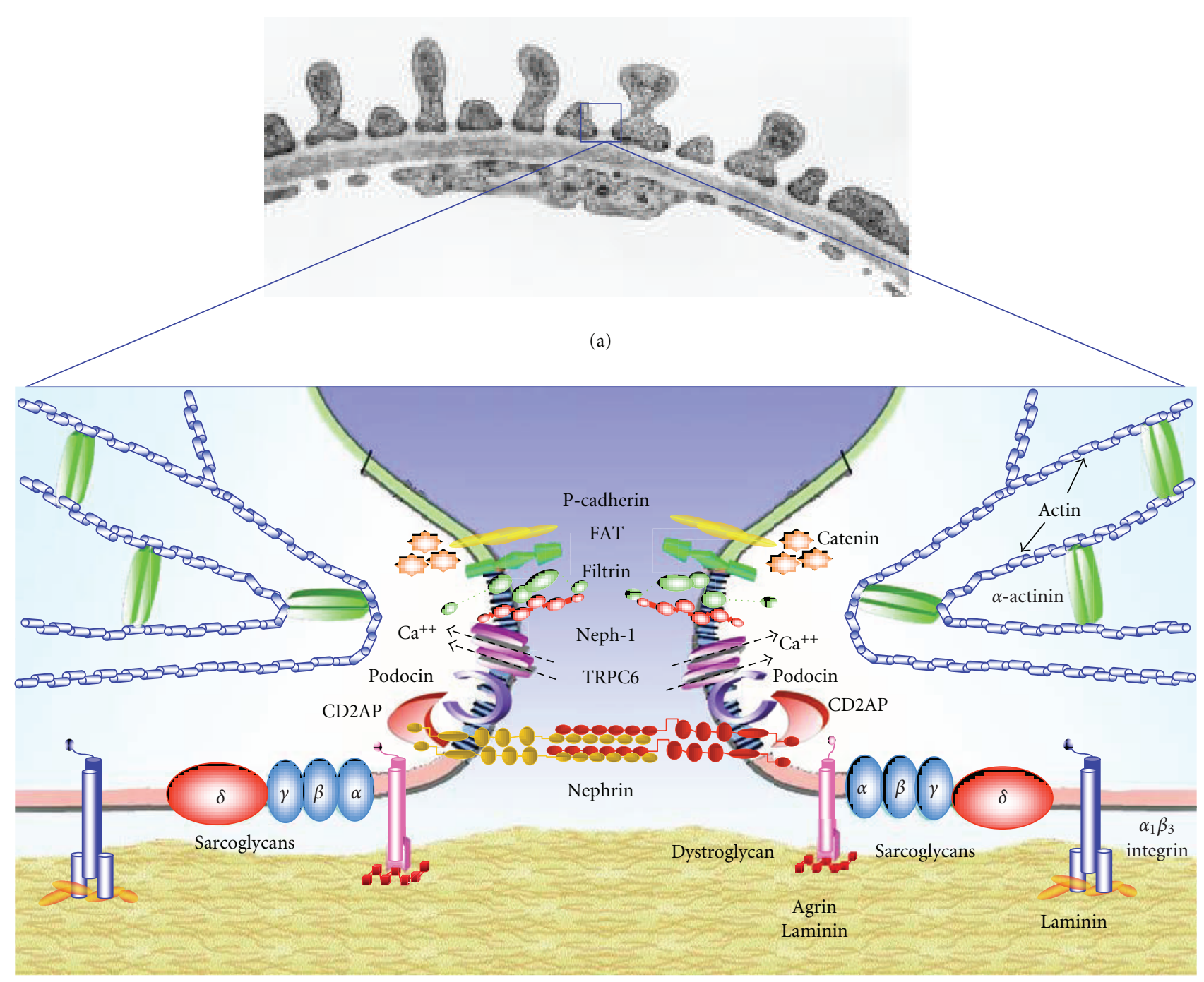

(b)

Figure 1: (a) Low-power view of glomerular filtration barrier in situ. The glomerular filter consists of three components: porous endothelium, glomerular basement membrane, and podocyte foot processes with the interposed slit membrane. Figure is transmission electron microscopy from a rat. Magnification: $B, \mathrm{x} \sim 48,000$. (b) Schematic drawing of the molecular equipment of the podocyte foot processes, similar to the area marked in Figure 1(a). See text for further explanations, (modified from [23]).

Podocyte detachment leaves the denuded GBM, and this may play an important role in the FSGS pathogenesis: podocytes have not proliferative capacity and cannot repopulate denuded areas, and a scar is formed by parietal ephitelial cells [7].

The glomerular basement membrane (GBM), responsible for the charge-selective property of glomerular filtration barrier, is organized as a highly cross-linked network of specific extracellular matrix proteins, such as type IV collagen, fibronectin, laminin, nidogen, and heparansulfate proteoglycans (HSPGs). The flexibility and dynamism of the GBM requires a constant turnover. In the adult glomerulus, the podocytes continue to add and assemble GBM components and secrete matrix modifying enzymes [43].

Genetic modifications of structural GBM proteins, such as type IV collagen, cause Alport syndrome (AS), a hereditary nephropathy associated with deafness [30]. Thickening, basket-wave splitting, and rarefaction of the GMB have been reported in other hereditary nephritis with Döhle-like inclusions in polymorphonuclear cells and/or thrombocytopenia with giant platelets. This condition is known as Alportlike syndrome or Fechtner syndrome (FTNS), when Döhlelike bodies are associated with macrothrombocytopenia (MTCP) and Epstein syndrome (EPTS) when no leukocyte inclusions are present. Recently, it has been shown that mutations in MYH9, the gene encoding for nonmuscle myosin heavy chain IIA (NMMHC-IIA), are responsible for Fechtner syndrome, Epstein syndrome, and other two MTCPs (Sebastian syndrome and May-Hegglin anomaly) without renal, ocular, or hearing defects (Table 1).

In the glomerulus, MYH9 mRNA and its protein are highly expressed by podocytes and colocalized with actin and 


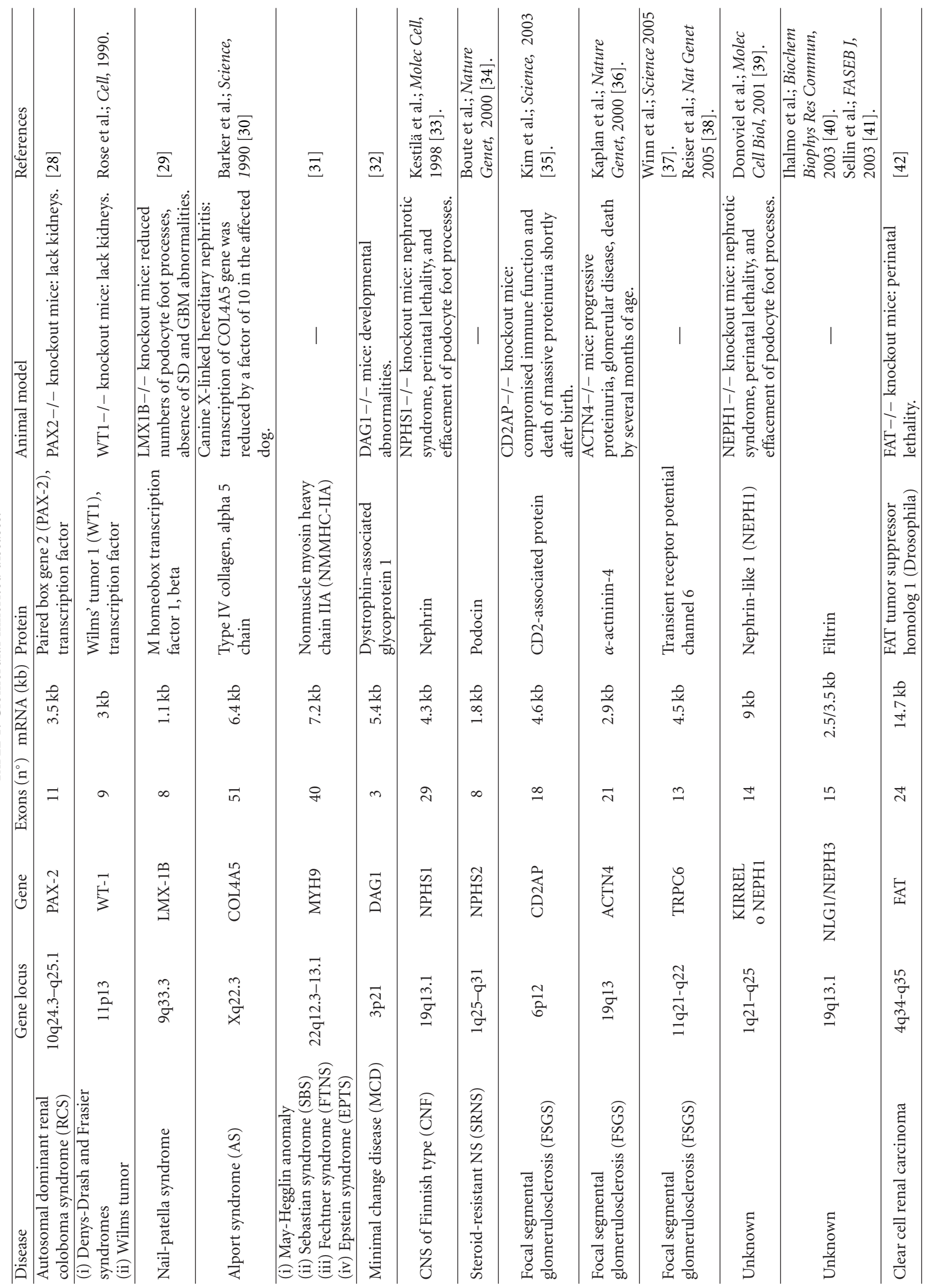


$\alpha$-actinin, suggesting that NMMHC-IIA could be an important component of the podocyte actin-myosin contractile apparatus and play a central role in maintaining capillary wall integrity [44-48].

\section{The Slit Diaphragm Complex}

Our knowledge of the molecular and structural composition of podocyte slit diaphragms have been improved in the past few years. The discovery of several novel slit diaphragm proteins, including nephrin, podocin, Zonula Occludens 1 (ZO-1), CD2-associated protein (CD2AP), P-cadherin, catenins, FAT1, Neph1-3, densin, and TRPC6 [33-38, 40, 41, $49,50]$, has helped to characterize the region of the SD as a critical locus of podocyte function (Figure 1). Moreover, mutations in the genes encoding for slit diaphragm proteins have been linked to a variety of inherited and sporadic glomerular diseases (Table 1).

The first protein located at the SD domain is nephrin, codified by NPHS1 (19q13.1), the gene responsible of congenital nephrotic syndrome of the Finnish type (CNF), a rare autosomal recessive disease with a highest incidence in Finland [51-53]. Nephrin is a large transmembrane protein of 1241 amino acids, belonging to the immunoglobulin (Ig) superfamily, with eight extracellular Ig-like motifs, a fibronectin type III-like, a transmembrane, and an intracellular domain [54, 55].

Nephrin is a critical structural component of the slit diaphragm complex: both CNF patients with severe NPHS1 mutations and knockout mice fail in foot process and slit diaphragm development and exhibit severe proteinuria already in utero [56].

Recently, Donoviel et al. identified NEPH1, a novel nephrin-like protein, that localizes to the slit diaphragm and causes congenital nephrotic syndrome in knockout mice. NEPH1 belongs to a family of three closely related proteins (NEPH1, NEPH2, NEPH3) with a common domain architecture [39].

Ihalmo et al., independently, identified NEPH3 gene, which they called NLG1 (nephrin-like gene 1). NLG1 or NEPH3 was localized to chromosome 19q13.1, immediately adjacent to the NPHS1 gene, and encodes a type I transmembrane protein, termed filtrin, which contains an extracellular region with five tandem immunoglobulin-like domains, a transmembrane region, and a cytoplasmic domain with a proline-rich region.

Another important protein of the slit diaphragm complex is podocin, an integral protein, homologous to the band-7 stomatin family [34]. Podocin is codified by NPHS2 (1q25-1q31), the gene responsible for autosomal recessive steroid-resistant nephrotic syndrome $[34,57,58]$. Due to its structural similarity to stomatin, podocin is predicted to have a hairpin-like membrane topology, with both $\mathrm{NH}_{2}$ - and $\mathrm{COOH}$-terminal intracellular domains. Podocin expression is restricted to podocytes. Podocin localizes to the podocyte foot process membrane and accumulates in an oligomeric form in lipid rafts of the slit diaphragm. Podocin associates with $\mathrm{CD} 2 \mathrm{AP}$ and nephrin via its $\mathrm{COOH}$-terminal domain
(Figure 1). These findings suggest that podocin may have a crucial role in the assembly of the SD complex, and, similar to the role of stomatin in erythrocytes, it may act as a scaffolding protein $[23,59,60]$.

A complex of nephrin, podocin, and CD2AP seems to be indispensable to maintain the structural integrity of the SD. CD2AP, initially described as a protein involved in T-cell activation, contains a coiled coil domain and three Src homology 3 (SH3) domains, which serve as attachment sites for other proteins. In CD2AP, knockout mice immune function was compromised and they died of massive proteinuria shortly after birth, suggesting an important role in glomerular function. Knockout mice presented flattened podocytes, mesangial cell hyperplasia, and extracellular matrix deposition. Mice with CD2AP haploinsufficiency developed glomerular changes at 9 months of age and had increased susceptibility to glomerular injury by nephrotoxic antibodies or immune complexes. Interestingly, some glomerular lesions of these mice exhibited a phenotype similar to human FSGS [61]. Kim et al. screened a population of 30 African Americans with idiopathic FSGS and 15 African Americans with HIV-associated FSGS for changes in CD2AP. Six distinct DNA variants, absent in control subjects, were detected in 10 of 45 patients. One nucleotide variant, altering the exon 7 splice acceptor site, was predicted to alter the expression of CD2AP. These findings and others implicate CD2AP as a determinant of human susceptibility to glomerular disease [35, 62-64].

Nephrin, podocin, and CD2AP are pivotal for slit diaphragm structural organisation, suggesting that these proteins could participate in a common cell-signaling pathway.

Huber et al. have demonstrated that both nephrin and $\mathrm{CD} 2 \mathrm{AP}$ interact in vivo with the $\mathrm{p} 85$ regulatory subunit of phosphoinositide $3-\mathrm{OH}$ kinase (PI3K). $\mathrm{PI} 3 \mathrm{~K}$ is the first protein demonstrated to interact with the cytoplasmic surface of SD protein complex in vivo. Nephrin and CD2AP recruit PI3K to the plasma membrane and, together with podocin, stimulate PI3K-dependent activation of the serinethreonine kinase, AKT. They demonstrate that nephrininduced AKT mediates phosphorylation of several target proteins in podocytes. Although the importance of this signalling is not fully understood, it is interesting that one target of nephrin-CD2AP-induced phosphorylation is Bad, a proapoptotic protein of the $\mathrm{Bcl}-2$ family; its phosphorylation and inactivation protect podocytes against apoptosis, suggesting that the nephrin-CD2AP-mediated AKT activity can regulate complex biological programs. These findings reveal a novel role for the slit diaphragm proteins and demonstrate that nephrin, CD2AP, and podocin proteins, in addition to their structural functions, initiate PI3K/AKT-dependent signal transduction in glomerular $[65,66]$.

In addition to these characterized podocyte proteins, the slit diaphragm area contains several other components, including P-cadherin, Zonula Occludens 1 (ZO-1), FAT, and densin. P-cadherin is associated with signalling proteins $\alpha-, \beta-, \gamma$-catenins. It colocalizes with the zona occludens associated protein (ZO-1), a member of the membrane associated guanylate kinase (MAGUK) family. FAT is a large cadherin homologue, localized to the slit diaphragm 
domain. FAT knockout mice exhibit perinatal lethality. The relation between P-cadherin, FAT, and nephrin is not known [67]. Densin is a new podocyte protein that belongs to the LAP protein family, characterized by leucin-rich repeats and PDZ domains. LAP proteins are involved in maintenance of cell shape and the apical-basal polarity, thus densin may be necessary for maintenance of podocyte polarity [50]. Finally, two recent studies by Winn et al. [37] and Reiser et al. [38] have identified six families with autosomal dominant hereditary FSGS caused by six different mutations in the gene encoding TRPC6, a nonselective cation channel. These mutations lead to a kidney disease with late onset and a variable rate of progression to FSGS. TRPC6 is a member of the transient receptor potential (TRP) family of nonselective cation channels [68, 69]. TRP channels have been implicated in different biological functions such as cell growth, ion homeostasis, mechanosensation, and phospholipase C-dependent calcium influx. Calcium, as a second messenger, affects many of these cellular functions. Will et al. have reported, in all affected members of a New Zeland family with autosomal dominant FSGS, a TRPC6 missense mutation, p.P112Q, within the first ankyrin repeats of the protein. TRPC $6^{\mathrm{P} 112 \mathrm{Q}}$ mutation increased peak calcium concentrations after stimulation with diacylglycerol and also potentiated angiotensin-II-mediated calcium signaling in HEK293 cells. The authors have speculated that the enhanced calcium signaling conferred by the TRPC6 ${ }^{\text {P112Q }}$ mutation might disrupt glomerular cells function or cause apoptosis and amplify injurious signals triggered by ligands such as angiotensin II, that promote kidney injury and proteinuria [37]. These findings are also consistent with the results reported by Reiser et al.: two out of five mutant proteins exhibited larger current amplitudes that wild-type TRPC6 channels. Using immunofluorescence and immunoelectron microscopy, Raiser et al. found that TRPC6 protein is enriched in podocytes and localized in podocyte foot processes near the slit diaphragms; moreover, TRPC6 interacts with nephrin and podocin but not with CD2AP [38, 69]. Moreover, we have recently demonstrated that TRPC6 mutations can also be detected in children with early onset and sporadic SRNS and described for the first time a de novo TRPC6 mutation in a severe form of pediatric collapsing glomerulosclerosis [70].

Thus, TRPC6 might belong, together with nephrin and podocin, to a signaling platform located at the slit diaphragm domain, suggesting a possible involvement of TRPC6 channels in regulating the dynamics of foot processes and slit diaphragm (Figure 1).

\section{The Slit Diaphragm Genes and Congenital Nephrotic Syndromes: Genotype/Phenotype Correlation}

The discovery of mutations in the genes coding for slit diaphragm proteins in patients with inherited nephrotic syndrome (NS) has been a breakthrough in both molecular and clinical research of glomerular diseases [71-78]. Moreover, mutations in the slit diaphragm genes have been reported in sporadic cases $[79,80]$. There is growing evidence that the presence of slit diaphragm gene defects has a great importance in clinical practice of nephrotic patients; in fact, the identification of mutations in nephrotic patients might allow the avoidance of unnecessary treatments, might permit the prediction of absence of recurrence after transplantation, and might allow for the provision of prenatal diagnosis to families at risk [81].

The best characterized inherited nephrotic syndromes are congenital nephrotic syndrome of the Finnish type (CNF) and Steroid Resistant Nephrotic Syndrome (SRNS), due to mutations in NPHS1 and NPHS2 genes, respectively. However, recently genes related to steroid-sensitive nephritic syndrome (SSNS) were also identified; finally, podocyte dysfunction is also seen as a component of several inherited multiorgan syndromes.

5.1. Congenital Nephrotic Syndrome of the Finnish Type $(\mathrm{CNF})$. CNF is an autosomal recessive disorder frequent in Finland $(1: 10,000)$, but it has also been described in various ethnic groups throughout the world [82]. The disease develops in utero, and a severe nephrotic syndrome, resistant to steroids or immunosuppressive drugs, is present from birth. Infants are premature with low birth weight and large placenta. Renal biopsy specimens show mild mesangial hypercellularity and extensive effacement of foot processes. Microcystic dilations of proximal tubules are common but not specific. Nutritional status and statural growth are poor, and children are highly susceptible to bacterial infections and thromboembolic complications. In patients with CNF who progress to ESRD between 3 and 8 years of age, the only long-term and life-saving treatment is renal transplantation $[51,52]$.

The CNF gene (NPHS1), encoding for nephrin, has been mapped to chromosome $19 q 13.1$ by Kestilä et al. using the positional cloning approach [33]. In Finnish patients, two main NPHS1 gene defects, Fin-major (c.121delCT) and Finminor (p.R1109X), were found in over 94\% of the CNF cases, suggesting the existence of two founder effects [53]. Recurrence of proteinuria after transplantation, as a result of the development of antinephrin antibodies, occurs in $20 \%$ of the patients with Fin-major/Fin-major genotype, which leads to the absence of nephrin in native kidney [83]. Outside Finland, CNF constitutes the commonest type of congenital nephrotic syndrome, but the exact incidence is unknown. Several non-Finnish cases emulate the classically severe clinical phenotype seen in Finland, and a variety of NPHS1 mutations distinct from Fin-major and Fin-minor have been detected [49, 74-76]. However, an unexplored area remains the milder disease phenotypes, with occasional remission of proteinuria [77]. It seems that NPHS1 mutations causing a total absence of nephrin expression and a complete flattening of foot processes are responsible for a severe, therapyresistant form of nephrotic syndrome; while patients with NPHS1 mutations causing only partially defective nephrin may still have slit diaphragms and respond to therapy [73].

To date, about 173 different mutations have been reported both in Finnish and non-Finnish patients. These 
mutations include small deletions, insertions, nonsense, missense, splice site, and promoter variations, and they are distributed throughout the gene, emphasizing a functional requirement for both extracellular and intracellular domains. A surprisingly large number of NPHS1 mutations are missense resulting in single amino acid substitutions, all located at the extracellular domain, particularly within immunoglobulin domains "hot spot" [84].

Nephrin is a signaling molecule, which stimulates mitogen-activated protein kinases. Nephrin-induced signaling is greatly enhanced by podocin, which binds to the cytoplasmic domain of nephrin. Mutational analysis suggests that abnormal or inefficient signaling through the nephrinpodocin complex contributes to podocyte dysfunction and proteinuria [65].

5.2. Steroid Resistant Nephrotic Syndrome (SRNS). Steroidresistant NS is characterized by an autosomal recessive transmission, onset of proteinuria between 3 months and 5 years, resistance to steroid treatment, rapid progression to ESRD, absence of recurrence after renal transplantation, and absence of extrarenal disorders. Minimal changes on early biopsy specimens and FSGS at later stages are observed [58]. The causative gene, NPHS2, encoding for podocin, was mapped to 1q25-q31 by positional cloning approach [34].

NPHS2 mutations were first described in children with familial steroid-resistant idiopathic nephrotic syndrome. More than 116 pathogenic mutations have been found to segregate with the disease [85-87]. These mutations alter the expression of the gene or the structure of the protein. Two mutations, the R138Q and the R138X, were recurrent: the first one was observed in patients originating from Germany or The Netherlands, and the second one in families with Israeli-Arab descent. The R138Q podocin is retained in the endoplasmic reticulum and loses its ability to recruit nephrin in lipid rafts [88].

Podocin mutations have also been reported in patients with congenital or infantile nephrotic syndrome. Schultheiss et al. [89] found NPHS2 gene mutations in 11/27 (41\%) patients with congenital nephrotic syndrome and NPHS1 gene mutations in 15/27 (55\%) patients. Caridi et al. [90] reported an infantile steroid-resistant nephrotic syndrome associated with FSGS in three children with a homozygous haplotype in which two mutations are present in cis (P20L and R168H). Tsukaguchi et al. analyzed NPHS2 gene in 30 FSGS families with adolescent or adult onset. In six of these families, the affected subjects were compound heterozygous for R229Q amino acid substitution, which has an allele frequency of $3.6 \%$ in control population. Using in vitro translated podocin and purified nephrin, it was found that nephrin bound poorly to R229Q podocin; these data suggest that the R229Q mutation alone is, probably, insufficient to cause FSGS but it might enhance susceptibly to renal injury in association with a second NPHS2 mutation or variants in other genes, such as nephrin. However, the clinical relevance of the R229Q variant is unknown [91]. Pereira et al. [92] found that R229Q polymorphism was associated with a 2.77 -fold increased risk of presenting microalbuminuria. It remains to be demonstrated whether this polymorphism is a risk factor for developing end-stage renal disease.

NPHS2 mutations have also been reported in 10 to 33\% of sporadic steroid-resistant NS, which represents a frequent cause of ESRD in children [57, 79]. Ruf et al. [86] studied 152 patients with sporadic FSGS and found that $32(21 \%)$ had homozygous or compound heterozygous mutations. Weber et al. [87] found a lower mutation rate of $6.4 \%$ in 172 patients with sporadic steroid-resistant nephrotic syndrome.

Podocin mutations are restricted to steroid-resistant patients. In a recent study, no podocin mutations were found in 124 children with steroid-responsive nephrotic syndrome, confirming the results of Frishberg et al. and Caridi et al. [57, $78,86]$. The identification of podocin mutations in sporadic cases of steroid-resistant nephrotic syndrome is important for therapeutic decisions and genetic counseling. None patients with sporadic steroid-resistant NS and podocin mutations had complete remission following cyclosporine or cyclophosphamide treatment; only few patients presented a partial remission after cyclosporine therapy, but longterm benefit of this treatment is not documented, and cyclosporine may be nephrotoxic in patients with persistent proteinuria. Thus, steroid-resistant patients should be tested for podocin mutations before giving immunosuppressive therapy. Rapid screening of these patients for NPHS2 mutation is possible because of the small size of the gene. However, it should be remembered that not all familial cases of steroid-resistant nephrotic syndrome are linked to NPHS2 gene, indicating that other genes remain to be identified. This is important to understand therapy results and for a possible multicenter therapeutic trials.

Finally, Koziell et al. [77] detected NPHS2 mutations in two patients with typical CNF in whom NPHS1 mutations were not found and mutations in both NPHS1 and NPHS2 genes were found in four cases with congenital FSGS (digenic inheritance). These data, confirmed successively by other studies $[87,89]$, indicate an epistatic gene interaction, resulting in a rare example of multiple allelic hits, and provide the first evidence for a functional interrelationship between nephrin and podocin. These findings demonstrate the genetic heterogeneity of congenital nephrotic syndrome and the absence of genotype/phenotype correlations. Congenital nephrotic syndrome may also be due to WT1 mutations and diffuse mesangial sclerosis. Currently, three genes are associated with congenital nephrotic syndrome: NPHS1, NPHS2, and WT1 $[79,93]$.

5.3. Steroid-Sensitive Nephrotic Syndrome (SSNS). Whereas gene identification has furthered the understanding of pathomechanisms in steroid-resistant nephrotic syndrome (SRNS), not even a gene locus is known for SSNS. Total genome linkage analysis was performed in a consanguineous SSNS kindred, 11 patients, to identify a gene locus for SSNS. Homozygosity mapping identified a locus for SSNS on chromosome 2p12-p13.2 [94].

This locus is not responsible for the disease in all SSNS families, demonstrating that, like SRSN, this phenotype is also genetically heterogeneous. In fact, other authors 
reported an extended SSNS Bedouin family with a high rate of consanguinity. The clinical presentation and steroid response of its 11 affected individuals were similar to those of sporadic SSNS, but it was not linked to any of the presently known chromosomal loci nor predicted to be caused by mutation in any one of a list of genes associated with nephrotic syndrome [95].

5.4. Diffuse Mesangial Sclerosis. Children with diffuse mesangial sclerosis appear normal at birth, with a normal birth weight and without placental enlargement. The nephrotic syndrome may be present at birth or even suspected in utero by the finding of an elevated plasma alpha-fetoprotein level in the mother or the discovery of large hyperechogenic kidneys [96]. Abnormalities in the PLCE1 gene, which encodes phospholipase $\mathrm{C}$ epsilon, appear to cause isolated diffuse mesangial sclerosis. In one study of 12 children from 6 families with the disease, homozygous truncating gene mutations in PLCE1 were found in eight children [97]. Phospholipase $\mathrm{C}$ epsilon is a member of the phospholipase family of enzymes that catalyzes the hydrolysis of polyphosphoinositides resulting in generation of second messengers (e.g., inositol-1,4,5-triphosphate), which are involved in cell growth and differentiation. A pathogenetic role for PLCE1 in glomerular development was supported by findings of disruption of the glomerular filtration barrier and edema in a PLCE1 knockout zebrafish model. How a PLCE1 gene defect results in changes in the glomerular nephrotic syndrome is unknown. One possible explanation is that phospholipase C epsilon interacts with GTPase-activating protein, which is known to interact with the slit diaphragm protein, nephrin. Perturbations of this normal interaction would have a downstream effect including the subsequent interaction of GTPase-activating protein with nephrin.

\section{Syndromic Disease}

6.1. WT1 Mutations. The WT1 gene encodes a transcriptional factor of the zinc finger protein family that is involved in kidney and gonadal development. WT1 has been localized to chromosome 11q13; it consists of ten exons and generates four different isoforms resulting from alternative splicing [98]. After birth, WT1 protein expression is restricted to renal podocytes where it probably contributes to maintain an adult differentiation. Germline heterozygous WT1 mutations have been extensively reported in the literature as the cause of Denys-Drash (DDS) and Frasier (FS) syndromes that are characterized by nephrotic syndrome, genitalia anomalies, and pseudohermaphroditism. Renal findings in DDS are predominantly characterized by diffuse mesangial sclerosis of early onset and rapid evolution to end-stage renal failure, while FS usually presents slow progressive focal segmental sclerosis (FSGS). WT1 mutations associated with nephrotic syndrome are restricted to exons 8 and 9, that represent a sort of hot-spot that may be easily investigated. The three major studies [99-101] overall confirm an incidence of WT1 mutation in patients under 18 years around 6-7\%. A most remarkable finding is that, in young females, this incidence is higher (10-12\%) and probably becoming the most frequent inherited cause of nephrotic syndrome under 18 years in this sex cohort. Moreover, we have demonstrated that WT1 splice mutations are not rare in females under 18 years with SRNS, frequently in absence of phenotype change typical of Frasier syndrome. In adults and children with SDNS, screening analysis is of no clinical value. WT1 hot spot mutation analysis should be routinely done in children with SRNS; if the molecular screening anticipates any further therapeutic approach, it may modify the long term therapeutic strategy [101].

6.2. LMX1B Gene. LMX1B gene mutations are associated with autosomal dominant nail-patella syndrome, a condition displaying dysplastic nails, hypoplastic patellae, and glomerulopathy with proteinuria and hematuria [102]. Its phenotype is highly variable, and the main pathologic finding is an altered GBM. LMX1B gene is a transcription factor that plays an important role in glomerular development, regulating the transcription of multiple genes integral for proper glomerular basement membrane formation and/or glomerular podocyte differentiation and function [103]. LMX1B binds to the putative enhancer sequence of COL4A4, the gene for alpha- 4 chain of collagen type IV [103].

6.3. LAMB2 Gene. LAMB2 gene mutations are associated with Pierson syndrome, an autosomal recessive syndrome characterized by congenital nephrotic syndrome with histologic lesions of diffuse mesangial sclerosis and ocular malformations (microcoria, abnormal lens with cataracts, and retinal abnormalities) [104]. LAMB2 gene encodes the laminin beta 2, a protein abundantly expressed in the glomerular basement membrane where it plays a role in anchoring and in the development of podocyte foot processes [105]. LAMB2 mutations have also been found in patients with congenital nephrotic syndrome and either no or less severe ocular abnormalities.

6.4. CD151 Deficiency. Recent work in humans has shown that the tetraspanin CD151 is essential for the function of the kidney, as mutations in CD151 have been identified in three patients presenting with hereditary nephrotic syndrome leading to end-stage renal failure, pretibial bullous skin lesions, sensorineural deafness, and thalassemia. CD151 is part of the tetraspanin family of proteins that are ubiquitously expressed, membrane-embedded proteins that share a similar structure, and form dynamic complexes with each other and with integrins. Mice deficient in CD151 develop proteinuria, FSGS, and kidney failure [106].

6.5. SMARCALI Gene. Immunoosseous dysplasia is a rare autosomic recessive disorder that presents with spondyloepiphyseal dysplasia, renal dysfunction, and T-cell immunodeficiency [107]. This syndrome is caused by mutations in SMARCALI gene that encodes for a widely expressed protein involved in the chromatin remodelling. The renal involvement is characterized by proteinuria, FSGS, and renal failure. 
6.6. Beta4 Integrin Mutation. The occurrence of congenital nephrotic-range proteinuria secondary to focal segmental glomerulosclerosis has been reported in an infant with epidermolysis bullosa and pyloric atresia (EB-PA) [108].

EB-PA is an autosomal recessively inherited disease manifesting in the neonatal period with blistering of the skin and mucous membranes, as well as congenital gastrointestinal abnormalities including esophageal, gastric, or duodenal atresia. Both lethal and nonlethal forms have been described. The condition is caused by mutations in the a 6 and b4 integrin genes, which are expressed in the hemidesmosomes of stratified epithelia. Most cases of EB-PA are associated with mutations in the b4 gene, ITGB4, located on the long arm of chromosome 17 [109]. Mutations in the a6 gene, ITGA6, located on the long arm of chromosome 2, are less frequent [110].

In the case reported by Kambham et al., a novel mutation in exon 31 of the b4 integrin gene, ITGB4, was identified. Authors proposed that the $\mathrm{b} 4$ integrin gene mutation led to expression of a dysfunctional protein important in the maintenance of normal glomerular permselectivity and podocyte integrity. The development of nephrotic-range proteinuria, without full nephrotic syndrome, is consistent with the role of $\mathrm{b} 4$ as a minor podocyte integrin. The failure to detect proteinuria more frequently in $\mathrm{EB}$ may relate to early mortality and the unique effect of this novel b4 integrin mutation on podocyte function.

6.7. Renal Disease and Mitochondrial Genetics. Mitochondrial diseases can give rise to various syndromes or association, namely, neurologic and neuromuscular diseases, cardiac, renal, hepatic, hematological and endocrinic, or dermatological presentations. Renal dysfunction associated with mitochondriopathies is generally a rare event. The most frequent renal symptom is proximal tubular dysfunction with a more or less complete de Toni-Debre-Fanconi Syndrome [111]. A few patients have been reported with tubular acidosis, Bartter Syndrome, chronic tubulointerstitial nephritis, or nephrotic syndrome. Any mode of inheritance can be observed: sporadic, autosomal dominant or recessive, or maternal inheritance [111].

Three cases that presented with central and peripheral nervous system involvement and with NS secondary to FSGS in the first decade of life were associated to ubiquinone deficiency [112]. More recently steroid-resistant NS or neonatal renal failure has also been described in patients who bore inherited COQ2 mutations [113]. Taken together, these data allow identification of a new entity within the category of mitochondrial cytopathies, characterized by inherited COQ2 mutations, proliferation of dysmorphic mitochondria, and primary glomerular damage. This new entity may be defined as "COQ2 nephropathy," because the kidney seems to be a primary target in some patients presenting with isolated renal symptoms [113]. COQ2 mutations cause a renal disease that is characterized by variable renal lesions and widespread proliferation of dysmorphic mitochondria in glomerular cells. The clinical picture can be heterogeneous, and neuromuscular symptoms may complicate the course of the disease. Early recognition of this new entity may be crucial, because clinical symptoms can improve after ubiquinone supplementation, and neurologic complications may be prevented [114].

FSGS lesions have already been associated with mutations in the mitochondrial genome $3243 \mathrm{~A} 3 \mathrm{G}$ in the tRNALeu(UUR) gene), which may cause isolated glomerular disease [114-116]. Podocyte damage secondary to inherited mitochondrial dysfunction may cause visceral cell depletion, accumulation of extracellular matrix, and ultimately sclerosis of the glomerular tuft. In other cases, the same mitochondrial disease seems to trigger epithelial cell proliferation (in particular podocyte proliferation), associated with GBM collapse. Whereas increased apoptosis of podocyte cells may explain the mechanisms underlying FSGS formation in mitochondrial cytopathies [117], it remains unclear why in some cases the pathway taken by injured podocytes leads to proliferative lesions [118].

Mitochondrial dysfunction and altered mitochondrial gene expression have also been documented in patients with NS secondary to nephrin mutations $[119,120]$ suggesting that, regardless of the initial insult, mitochondria play an important role in podocyte metabolism and may be actively involved in the pathophysiology of various forms of NS.

6.8. Limp2 Gene. Lysosomal integral membrane protein type 2 (LIMP-2), the product of the SCARB2 gene (MIM 602257), is a member of the CD36 superfamily of proteins [121]. The absence of this protein in mice causes urinary and neurological alterations, associated with impaired vesicular trafficking and distribution of apically expressed proteins [122]. A deficiency in LIMP-2 resulting from a nonsense mutation in the SCARB2 gene has been recently described in humans [123]. When in a homozygous state, the mutation was associated with progressive myoclonic epilepsy without intellectual impairment and a nephrotic syndrome with strong accumulation of $\mathrm{Clq}$ in capillary loops of the kidney, whereas healthy parents were heterozygous for the mutation. The main clinical features are nephrotic syndrome, normocytic normochromic anemia, and thrombocytopenia.

The histological analysis of the medullar zone in renal material revealed extensive tubular alterations with isometric vacuolization in distal and collecting tubules and the presence of granular material in cortical tubules without inflammatory infiltration deposits [122].

Berkovic et al. [124] described LIMP-2 mutations in three patients with action myoclonus-renal failure syndrome. Action myoclonus-renal failure syndrome (AMRF [MIM 254900]) is a lethal inherited form of progressive myoclonus epilepsy associated with renal failure. It typically presents at 15-25 years with proteinuria evolving into renal failure or with neurological symptoms (tremor, action myoclonus, seizures, and later ataxia). The renal pathology is of focal glomerulosclerosis, sometimes with features of glomerular collapse. The disorder was mapped to 4q13-21, and microarray-expression analysis identified SCARB2/Limp2, which encodes a lysosomal membrane protein, as the likely candidate. Mutations in SCARB2/Limp2 were found 
in all three families used for mapping and subsequently confirmed in two other unrelated AMRF families. The mutations were associated with lack of SCARB2 protein. The heterogeneous pathology in the kidney and brain suggests that SCARB2/Limp2 has pleiotropic effects that may be relevant to understanding the pathogenesis of other forms of glomerulosclerosis or collapse and myoclonic epilepsies. However, mutations in SCARB2 might account for unsolved cases of progressive myoclonus epilepsy (PME) without renal impairment, especially those resembling UnverrichtLundborg disease (ULD) [125]. Finally, contrary to earlier proposals, LIMB 2 mutations share no features with CharcotMarie-Tooth disease both at the clinical and neurophysiological levels [124, 125].

\section{Podocyte Cytoskeleton and Familial FSGS}

The major processes of podocytes have an abundant and dynamic cytoskeleton composed mainly of actin-rich microfilaments, containing several actin-associated proteins, such as myosin, synaptopodin, and $\alpha$-actinin. Podocyte damage and proteinuria can result from cytoskeletal alterations too, rather than direct alterations in slit diaphragm proteins.

Kaplan et al. found linkage to chromosome 19q13, in three families with clear evidence of autosomal dominant inheritance of FSGS, with late onset. They analyzed the NPHS1 gene, located in this interval, and found no mutations associated with this disorder. By BLAST analysis, they considered ACTN4, encoding $\alpha$-actninin-4, as candidate gene, and a mutational screening was performed in affected individuals of families. $\alpha$-actninin- 4 , an actin-filament crosslinking protein (Figure 1), is highly expressed in glomerular podocytes and involved in nonmuscle cytoskeletal function. ACTN4 missense mutations were identified in affected members of each family. Mutant $\alpha$-actinin-4 protein binds F-actin more strongly than wild-type $\alpha$-actinin-4. These data suggest that mutations in ACTN4 gene might cause an increased affinity for actin filaments, and podocyte actin cytoskeleton may be altered in this group of patients. Interestingly, $\alpha$ actinin-4 deficiency not only causes recessive glomerular disease, but also increases cellular mortality [36]. Thus, lesions which compromise cytoskeletal functions of podocyte appear to result in a slowly progressive loss of podocyte, the hallmark of FSGS.

Consistent with this hypothesis are also the results reported by Winn et al. and Reiser et al. in two recent works, in which a familial late onset form of FSGS, linked to chromosome $11 \mathrm{q}$ and caused by mutations in the gene encoding TRPC6, was described [37, 38]. A failure in the receptor-mediated influx of $\mathrm{Ca}^{++}$through mutated TRPC6 protein, a nonselective cation channel, might underlie the new 11q-linked FSGS. Cytoplasmatic calcium concentrations are tightly regulated to prevent cellular damage. The authors speculate that mutated TRPC6 channels might disrupt glomerular homeostasis and/or cause podocyte apoptosis. The onset of kidney disease linked to mutations in TRPC6 gene occurs at a relatively advanced age. There are two possible explanations of this finding: podocytes express several other
TRPC channel subtypes, so late onset of disease might be caused by compensation for impaired TRPC6 function by other channels; in addition, TRPC6 mutations might cause only a minor damage in podocyte function and lead to irreversible alterations in the presence of a second glomerular insults $[69,126]$. However, to better understand the exact function of TRPC channels in podocytes and their role in familial and acquired forms of FSGS, additional studies should be performed.

Recently, Brown et al. found heterozygous mutations in the formin INF2 gene segregating with FSGS in $11(12 \%)$ of 93 families with age at diagnosis and ESKD varying from 11 to 72 years and 13 to 67 years, respectively [127]. This finding has been successively confirmed by Boyer et al. in a cohort of 54 families with a glomerular proteinuric disorder of apparent $\mathrm{AD}$ inheritance and documented FSGS in at least one affected member. Missense INF2 mutations were found in nine families (28 patients), translating to a detection rate of $16.7 \%$ [ 128 ].

INF2 is a member of the formin family of actinregulating proteins that accelerate actin polymerization [129]. To date, 15 mammalian formin genes have been identified, among which are the best studied diaphanousrelated formins (DRF): $\mathrm{mDia} 1, \mathrm{mDia} 2$, and $\mathrm{mDia} 3$. In the C-terminal half, DRF proteins contain the forming homology domains $\mathrm{FH} 1 / \mathrm{FH} 2$ and the diaphanous autoregulatory domain (DAD) region, whereas the diaphanous inhibitory domain (DID) is localized at the N-terminal half [4]. Interestingly, all of the 13 INF2 mutations associated to FSGS lie within the DID region of the protein [127, 128], and six of them are localized in the corresponding INF2 region of a mDial DID subdomain interacting with IQ motif-containing GTPase-activating protein (IQGAP1) [128]. IQGAP1 has been identified as a Dial-binding protein that is necessary for its subcellular location [130]; it is also involved in actin cytoskeleton dynamics [131] and has been shown to interact with the podocyte proteins nephrin [132] and PLCE1 [133]. Although, the exact mechanism explaining how mutations in the INF2 gene may lead to a proteinuric phenotype remains unclear, and these first observations reinforce the idea of podocytes as dynamic structures that are extremely sensitive to alterations in the spatial or temporal regulation of the actin cytoskeleton. Thus, INF2 seems to be a major gene of AD FSGS. Screening for INF2 mutations, at least in exons 2 to 4 , encoding the DID domain, should be strongly considered in patients with an AD familial history of FSGS, even before ACTN4 and TRPC6.

\section{The Other Side of the Moon: Immunopathogenesis of Idiopathic Nephritic Syndrome}

Although recent genetic approaches have elucidated the disease pathogenesis through the discovery of several podocyte genes mutated in distinct forms of hereditary nephrosis, the molecular basis of minimal change nephritis syndrome and FSGS with relapse remains still unclear. In this setting, the immune system seems to play a critical role in the active 
phase of this disease through disturbances involving several cell subsets, mainly T cells.

MCNS may be a systemic disorders of T-cell function and cell-mediated immunity [134]. Nowadays, it is quite clear that MCNS is the most common kidney disease associated with primary immunological disorders and that the sensitivity to steroid and immunosuppressive therapy is an important argument in favour of the immune origin of the MCNS [135]. Recent reports suggest a clonal expansion of CD8+ T cells expressing the memory T-cell marker, CD45RO [136]. and of CD4+ T cell expressing the CD25 antigen, the IL-2 receptor chain in long-lasting, active disease. Moreover, also the native immune system seems to be involved in MCNS, probably through the signalling pathway of the NF$\kappa \mathrm{B}$ [137]. It has been shown that peripheral mononuclear cells, including $\mathrm{T}$ cells, exhibit high NF- $\kappa \mathrm{B}$ binding activity involving the p50/p65 complexes during relapses, which returned to basal levels during remissions [138]. There is a T-cell commitment towards a Th2 phenotype in MCNS that might explain why these patients often display a defect in delayed-type hypersensitivity response, suggesting an abnormal Th1-dependent cellular immunity [135].

Moreover, a second set of signals mediated by coreceptors is needed to promote $\mathrm{T}$-cell proliferation, lymphokine secretion, and effector functions. In this setting, Cmip is as new discovered gene of unknown function, which is initially identified in T lymphocytes of patients with MCNS [139]. c-mip interferes at different levels of cell signaling and in particular is involved in the Th2 signaling pathway [140].

An hypothesis unifying T-cell disorders and podocyte dysfunction has recently been proposed by Zhang and coworkers [135]. The functional alterations allowing to nephritic proteinuria could result from the downregulation of transduction pathways playing a key role in slit diaphragm function such as the nephrin-mediated pathway. It is possible that the circulating factor is somehow linked to the NF- $\kappa \mathrm{B}$ pathway and that podocyte and immune cells might share the same molecular defect [135].

\section{Conclusions}

Recent molecular studies have allowed a better understanding of structure and function of glomerular filtration barrier.

Nephrin seems to be the main member of the slit diaphragm, where it forms a zipper-like ultrafilter structure; podocin and CD2AP, instead, have probably the function to connect the cytoplasmic domain of nephrin to cytoskeleton and lipid rafts of the SD. Moreover, the latter findings on ACTN4, TRPC6, and INF2 proteins suggest an important role of cytoskeletal dynamics in the normal maintenance of podocyte function.

Nephrotic syndrome is a genetically heterogeneous condition. In general, recessive mutations in NPHS1, NPHS2, and PLCE1 are associated with more severe disease with earlier onset proteinuria and ESRD presenting in infancy and throughout childhood, although some milder cases have also been noted. By contrast, dominant mutations in ACTN4, TRPC6, and INF2 are associated with milder disease with later onset proteinuria in the second decade and ESRD in the third and fourth decades of life.

This new important discoveries may provide useful guidance to the clinicians in deciding whether a course of immunosuppressive drug treatment is appropriate. However, additional molecular genetics and in vivo studies should be improved to apply this new knowledge for the development of comprehensive molecular diagnostic test and new mechanism-based therapeutic tools.

\section{Acknowledgments}

The authors thank Professor Rodolfo Bracci for critically reading the paper. They also thank Eustacchio Montemurno and Roberta Trunzo (University of Foggia) for technical support.

\section{References}

[1] S. Somlo and P. Mundel, "Getting a foothold in nephrotic syndrome," Nature Genetics, vol. 24, no. 4, pp. 333-335, 2000.

[2] K. Tryggvason and J. Wartiovaara, "Molecular basis of glomerular permselectivity," Current Opinion in Nephrology and Hypertension, vol. 10, no. 4, pp. 543-549, 2001.

[3] K. Endlich, W. Kriz, and R. Witzgall, "Update in podocyte biology," Current Opinion in Nephrology and Hypertension, vol. 10, no. 3, pp. 331-340, 2001.

[4] A. A. Eddy and H. W. Schnaper, "The nephrotic syndrome: from the simple to the complex," Seminars in Nephrology, vol. 18, no. 3, pp. 304-316, 1998.

[5] W. E. Smoyer and P. Mundel, "Regulation of podocyte structure during the development of nephrotic syndrome," Journal of Molecular Medicine, vol. 76, no. 3-4, pp. 172-183, 1998.

[6] J. Reiser, G. von Gersdorff, M. Simons et al., "Novel concepts in understanding and management of glomerular proteinuria," Nephrology Dialysis Transplantation, vol. 17, no. 6, pp. 951-955, 2002.

[7] L. Barisoni and P. Mundel, "Podocyte biology and the emerging understanding of podocyte diseases," American Journal of Nephrology, vol. 23, no. 5, pp. 353-360, 2003.

[8] M. J. Karnovsky and S. K. Ainsworth, "The structural basis of glomerular filtration," Advances in Nephrology from the Necker Hospital, vol. 2, pp. 35-60, 1972.

[9] J. F. Armstrong, M. H. Kaufman, V. van Heyningen, and J. B. Bard, "Embryonic kidney rudiments grown in adult mice fail to mimic the Wilms' phenotype, but show strain-specific morphogenesis," Experimental Nephrology, vol. 1, no. 3, pp. 168-174, 1993.

[10] J. Pelletier, W. Bruening, F. P. Li, D. A. Haber, T. Glaser, and D. E. Housman, "WT1 mutations contribute to abnormal genital system development and hereditary Wilms' tumour," Nature, vol. 353, no. 6343, pp. 431-434, 1991.

[11] S. E. Quaggin, G. B. van den Heuvel, and P. Igarashi, "Pod-1, a mesoderm-specific basic-helix-loop-helix protein expressed in mesenchymal and glomerular epithelial cells in the developing kidney," Mechanisms of Development, vol. 71, no. 1-2, pp. 37-48, 1998.

[12] M. Takemoto, L. He, J. Norlin et al., "Large-scale identification of genes implicated in kidney glomerulus development and function," EMBO Journal, vol. 25, no. 5, pp. 1160-1174, 2006. 
[13] V. S. Sadl, F. Jin, J. Yu et al., "The mouse Kreisler (Krml1/MafB) segmentation gene is required for differentiation of glomerular visceral epithelial cells," Developmental Biology, vol. 249, no. 1, pp. 16-29, 2002.

[14] T. Kume, K. Deng, and B. L. M. Hogan, "Minimal phenotype of mice homozygous for a null mutation in the forkhead/winged helix gene, Mf2," Molecular and Cellular Biology, vol. 20, no. 4, pp. 1419-1425, 2000.

[15] S. D. Dreyer, G. Zhou, A. Baldini et al., "Mutations in LMX1B cause abnormal skeletal patterning and renal dysplasia in nail patella syndrome," Nature Genetics, vol. 19, no. 1, pp. 47-50, 1998.

[16] A. Caricasole, A. Duarte, S. H. Larsson et al., "RNA bind-ing by the Wilms tumor suppressor zinc finger proteins," Proceedings of the National Academy of Sciences of the United States of America, vol. 93, no. 15, pp. 7562-7566, 1996.

[17] I. A. Drummond, H. D. Rupprecht, P. Rohwer-Nutter et al., "DNA recognition by splicing variants of the Wilms' tumor suppressor, WT1," Molecular and Cellular Biology, vol. 14, no. 6, pp. 3800-3809, 1994.

[18] Y. Yang, C. Jeanpierre, G. R. Dressler, M. Lacoste, P. Niaudet, and M. C. Gubler, "WT1 and PAX-2 podocyte expression in Denys-Drash syndrome and isolated diffuse mesangial sclerosis," American Journal of Pathology, vol. 154, no. 1, pp. 181192, 1999.

[19] L. Barisoni, M. Mokrzycki, L. Sablay, M. Nagata, H. Yamase, and P. Mundel, "Podocyte cell cycle regulation and proliferation in collapsing glomerulopathies," Kidney International, vol. 58, no. 1, pp. 137-143, 2000.

[20] S. E. Quaggin, L. Schwartz, S. Cui et al., "The basic-helixloop-helix protein Pod 1 is critically important for kidney and lung organogenesis," Development, vol. 126, no. 24, pp. 5771$5783,1999$.

[21] S. E. Quaggin, G. B. van den Heuvel, and P. Igarashi, "Pod-1, a mesoderm-specific basic-helix-loop-helix protein expressed in mesenchymal and glomerular epithelial cells in the developing kidney," Mechanisms of Development, vol. 71, no. 1-2, pp. 37-48, 1998.

[22] V. S. Sadl, A. Sing, L. Mar, F. Jin, and S. P. Cordes, "Analysis of hindbrain patterning defects caused by the kreislerenu mutation reveals multiple roles of Kreisler in hindbrain segmentation," Developmental Dynamics, vol. 227, no. 1, pp. 134-142, 2003.

[23] D. Kerjaschki, "Caught flat-footed: podocyte damage and the molecular bases of focal glomerulosclerosis," Journal of Clinical Investigation, vol. 108, no. 11, pp. 1583-1587, 2001.

[24] H. Chen, Y. Lun, D. Ovchinnikov et al., "Limb and kidney defects in Lmxlb mutant mice suggest an involvement of LMX1B in human nail patella syndrome," Nature Genetics, vol. 19, no. 1, pp. 51-55, 1998.

[25] S. Adler, "Characterization of glomerular epithelial cell matrix receptors," American Journal of Pathology, vol. 141, no. 3, pp. 571-578, 1992.

[26] H. M. Regele, E. Fillipovic, B. Langer et al., "Glomerular expression of dystroglycans is reduced in minimal change nephrosis but not in focal segmental glomerulosclerosis," Journal of the American Society of Nephrology, vol. 11, no. 3, pp. 403-412, 2000.

[27] C. J. Raats, J. van den Born, M. A. H. Bakker et al., "Expression of agrin, dystroglycan, and utrophin in normal renal tissue and in experimental glomerulopathies," American Journal of Pathology, vol. 156, no. 5, pp. 1749-1765, 2000.

[28] A. J. Pilz, S. Povey, P. Gruss, and C. M. Abbott, "Mapping of the human homologs of the murine paired-box-containing genes," Mammalian Genome, vol. 4, no. 2, pp. 78-82, 1993.
[29] C. A. Iannotti, H. Inoue, E. Bernal et al., "Identification of a human LMX1 (LMX1.1)-related gene, LMX1.2: tissuespecific expression and linkage mapping on chromosome 9," Genomics, vol. 46, no. 3, pp. 520-524, 1997.

[30] D. F. Barker, S. L. Hostikka, J. Zhou et al., "Identification of mutations in the COL4A5 collagen gene in Alport syndrome," Science, vol. 248, no. 4960, pp. 1224-1227, 1990.

[31] K. E. Heath, A. Campos-Barros, A. Toren et al., "Nonmuscle myosin heavy chain IIA mutations define a spectrum of autosomal dominant macrothrombocytopenias: mayhegglin anomaly and Fechtner, Sebastian, Epstein, and alport-like syndromes," American Journal of Human Genetics, vol. 69, no. 5, pp. 1033-1045, 2001.

[32] O. Ibraghimov-Beskrovnaya, A. Milatovich, T. Ozcelik et al., "Human dystroglycan: skeletal muscle cDNA, genomic structure, origin of tissue specific isoforms and chromosomal localization," Human Molecular Genetics, vol. 2, no. 10, pp. 1651-1657, 1993.

[33] M. Kestilä, U. Lenkkeri, M. Männikkö et al., "Positionally cloned gene for a novel glomerular protein-nephrin-is mutated in congenital nephrotic syndrome," Molecular Cell, vol. 1, no. 4, pp. 575-582, 1998.

[34] N. Boute, O. Gribouval, S. Roselli et al., "NPHS2, encoding the glomerular protein podocin, is mutated in autosomal recessive steroid-resistant nephrotic syndrome," Nature Genetics, vol. 24, no. 4, pp. 349-354, 2000.

[35] J. M. Kim, H. Wu, G. Green et al., "CD2-associated protein haploinsufficiency is linked to glomerular disease susceptibility," Science, vol. 300, no. 5623, pp. 1298-1300, 2003.

[36] J. M. Kaplan, S. H. Kim, K. N. North et al., "Mutations in ACTN4, encoding $\alpha$-actinin-4, cause familial focal segmental glomerulosclerosis," Nature Genetics, vol. 24, no. 3, pp. 251256, 2000.

[37] M. P. Winn, P. J. Conlon, K. L. Lynn et al., "Medicine: a mutation in the TRPC6 cation channel causes familial focal segmental glomerulosclerosis," Science, vol. 308, no. 5729, pp. 1801-1804, 2005.

[38] J. Reiser, K. R. Polu, C. C. Möller et al., “TRPC6 is a glomerular slit diaphragm-associated channel required for normal renal function," Nature Genetics, vol. 37, no. 7, pp. 739-744, 2005.

[39] D. B. Donoviel, D. D. Freed, H. Vogel et al., "Proteinuria and perinatal lethality in mice lacking NEPH1, a novel protein with homology to NEPHRIN," Molecular and Cellular Biology, vol. 21, no. 14, pp. 4829-4836, 2001.

[40] P. Ihalmo, T. Palmén, H. Ahola, E. Valtonen, and H. Holthöfer, "Filtrin is a novel member of nephrin-like proteins," Biochemical and Biophysical Research Communications, vol. 300, no. 2, pp. 364-370, 2003.

[41] L. Sellin, T. B. Huber, P. Gerke, I. Quack, H. Pavenstädt, and G. Walz, "NEPH1 defines a novel family of podocin interacting proteins," FASEB Journal, vol. 17, no. 1, pp. 115-117, 2003.

[42] J. Dunne, A. M. Hanby, R. Poulsom et al., "Molecular cloning and tissue expression of FAT, the human homologue of the Drosophila fat gene that is located on chromosome 4q34-q35 and encodes a putative adhesion molecule," Genomics, vol. 30, no. 2, pp. 207-223, 1995.

[43] B. G. Hudson, S. T. Reeders, and K. Tryggvason, "Type IV collagen: structure, gene organization, and role in human diseases. Molecular basis of goodpasture and alport syndromes and diffuse leiomyomatosis," Journal of Biological Chemistry, vol. 268, no. 35, pp. 26033-26036, 1993.

[44] M. Simons, M. Wang, O. W. McBride et al., "Human nonmuscle myosin heavy chains are encoded by two genes 
located on different chromosomes," Circulation Research, vol. 69, no. 2, pp. 530-539, 1991.

[45] A. Toren, N. Amariglio, G. Rozenfeld-Granot et al., "Genetic linkage of autosomal-dominant Alport syndrome with leukocyte inclusions and macrothrombocytopenia (Fechtner syndrome) to chromosome 22q11-q13," American Journal of Human Genetics, vol. 65, no. 6, pp. 1711-1717, 1999.

[46] S. Kunishima, T. Kojima, T. Tanaka et al., "Mapping of a gene for May-Hegglin anomaly to chromosome 22q," Human Genetics, vol. 105, no. 5, pp. 379-383, 1999.

[47] C. Arrondel, N. Vodovar, B. Knebelmann et al., "Expression of the nonmuscle myosin heavy chain IIA in the human kidney and screening for MYH9 mutations in Epstein and Fechtner syndromes," Journal of the American Society of Nephrology, vol. 13, no. 1, pp. 65-74, 2002.

[48] J. R. Sellers, "Myosins: a diverse superfamily," Biochimica et Biophysica Acta, vol. 1496, no. 1, pp. 3-22, 2000.

[49] U. Lenkkeri, M. Männikkö, P. McCready et al., "Structure of the gene for congenital nephrotic syndrome of the Finnish type (NPHS1) and characterization of mutations," American Journal of Human Genetics, vol. 64, no. 1, pp. 51-61, 1999.

[50] H. Ahola, E. Heikkilä, E. Åström et al., "A novel protein, densin, expressed by glomerular podocytes," Journal of the American Society of Nephrology, vol. 14, no. 7, pp. 1731-1737, 2003.

[51] N. P. Huttunen, J. Rapola, J. Vilska, and N. Hallman, "Renal pathology in congenital nephrotic syndrome of Finnish type: a quantitative light microscopic study on 50 patients," International Journal of Pediatric Nephrology, vol. 1, no. 1, pp. 10-16, 1980.

[52] J. Khoshnoodi and K. Tryggvason, "Congenital nephrotic syndromes," Current Opinion in Genetics and Development, vol. 11, no. 3, pp. 322-327, 2001.

[53] M. Männikkö, M. Kestilä, C. Holmberg et al., "Fine mapping and haplotype analysis of the locus for congenital nephrotic syndrome on chromosome 19q13.1," American Journal of Human Genetics, vol. 57, no. 6, pp. 1377-1383, 1995.

[54] V. Ruotsalainen, P. Ljungberg, J. Wartiovaara et al., "Nephrin is specifically located at the slit diaphragm of glomerular podocytes," Proceedings of the National Academy of Sciences of the United States of America, vol. 96, no. 14, pp. 7962-7967, 1999.

[55] K. Tryggvason, "Unraveling the mechanisms of glomerular ultrafiltration: nephrin, a key component of the slit diaphragm," Journal of the American Society of Nephrology, vol. 10, no. 11, pp. 2440-2445, 1999.

[56] H. Putaala, R. Soininen, P. Kilpeläinen, J. Wartiovaara, and $\mathrm{K}$. Tryggvason, "The murine nephrin gene is specifically expressed in kidney, brain and pancreas: inactivation of the gene leads to massive proteinuria and neonatal death," $\mathrm{Hu}$ man Molecular Genetics, vol. 10, no. 1, pp. 1-8, 2001.

[57] Y. Frishberg, C. Rinat, O. Megged, E. Shapira, S. Feinstein, and A. Raas-Rothschild, "Mutations in NPHS2 encoding podocin are a prevalent cause of steroid-resistant nephrotic syndrome among Israeli-Arab children," Journal of the American Society of Nephrology, vol. 13, no. 2, pp. 400-405, 2002.

[58] A. Fuchshuber, O. Gribouval, V. Ronner et al., "Clinical and genetic evaluation of familial steroid-responsive nephrotic syndrome in childhood," Journal of the American Society of Nephrology, vol. 12, no. 2, pp. 374-378, 2001.

[59] K. Schwarz, M. Simons, J. Reiser et al., "Podocin, a raft-associated component of the glomerular slit diaphragm, interacts with CD2AP and nephrin," Journal of Clinical Investigation, vol. 108, no. 11, pp. 1621-1629, 2001.
[60] C. Antignac, "Genetic models: clues for understanding the pathogenesis of idiopathic nephrotic syndrome," Journal of Clinical Investigation, vol. 109, no. 4, pp. 447-449, 2002.

[61] N. Y. Shih, J. Li, V. Karpitskii et al., "Congenital nephrotic syndrome in mice lacking CD2-associated protein," Science, vol. 286, no. 5438, pp. 312-315, 1999.

[62] G. Wolf and R. A. K. Stahl, "CD2-associated protein and glomerular disease," The Lancet, vol. 362, no. 9397, pp. 17461748, 2003.

[63] M. Gigante, P. Pontrelli, E. Montemurno et al., "CD2AP mutations are associated with sporadic nephrotic syndrome and focal segmental glomerulosclerosis (FSGS)," Nephrology Dialysis Transplantation, vol. 24, no. 6, pp. 1858-1864, 2009.

[64] M. M. Löwik, P. J. T. A. Groenen, I. Pronk et al., "Focal segmental glomerulosclerosis in a patient homozygous for a CD2AP mutation," Kidney International, vol. 72, no. 10, pp. 1198-1203, 2007.

[65] T. B. Huber, M. Köttgen, B. Schilling, G. Walz, and T. Benzing, "Interaction with podocin facilitates nephrin signaling," Journal of Biological Chemistry, vol. 276, no. 45, pp. 4154341546, 2001.

[66] T. B. Huber, B. Hartleben, J. Kim et al., "Nephrin and CD2AP associate with phosphoinositide 3-OH kinase and stimulate AKT-dependent signaling," Molecular and Cellular Biology, vol. 23, no. 14, pp. 4917-4928, 2003.

[67] T. Inoue, E. Yaoita, H. Kurihara et al., "FAT is a component of glomerular slit diaphragms," Kidney International, vol. 59, no. 3, pp. 1003-1012, 2001.

[68] C. Montell, "The TRP superfamily of cation channels," Science Signaling, vol. 2005, no. 272, article re3, 2005.

[69] T. Gudermann, "A new TRP to kidney disease," Nature Genetics, vol. 37, no. 7, pp. 663-664, 2005.

[70] M. Gigante, G. Caridi, E. Montemurno et al., "TRPC6 mutations in children and steroid resistant nephrotic syndrome and atypical phenotypes," Clinical Journal of the American Society of Nephrology, vol. 6, no. 7, pp. 1626-1634, 2011.

[71] H. Jalanko, "Pathogenesis of proteinuria: lessons learned from nephrin and podocin," Pediatric Nephrology, vol. 18, no. 6, pp. 487-491, 2003.

[72] E. Machuca, G. Benoit, F. Nevo et al., "Genotype-phenotype correlations in non-Finnish congenital nephrotic syndrome," Journal of the American Society of Nephrology, vol. 21, no. 7, pp. 1209-1217, 2010.

[73] J. Patrakka, M. Kestila, J. Wartiovaara et al., "Congenital nephrotic syndrome (NPHS1): features resulting from different mutations in Finnish patients," Kidney International, vol. 58, no. 3, pp. 972-980, 2000.

[74] O. Beltcheva, P. Martin, U. Lenkkeri, and K. Tryggvason, "Mutation spectrum in the nephrin gene (NPHS1) in congenital nephrotic syndrome," Human Mutation, vol. 17, no. 5, pp. 368-373, 2001.

[75] K. Aya, H. Tanaka, and Y. Seino, "Novel mutation in the nephrin gene of a Japanese patient with congenital nephrotic syndrome of the Finnish type," Kidney International, vol. 57, no. 2, pp. 401-404, 2000.

[76] M. Gigante, F. Monno, R. Roberto et al., "Congenital nephrotic syndrome of the Finnish type in Italy: a molecular approach," Journal of Nephrology, vol. 15, no. 6, pp. 696-702, 2002.

[77] A. Koziell, V. Grech, S. Hussain et al., "Genotype/phenotype correlations of NPHS1 and NPHS2 mutations in nephrotic syndrome advocate a functional inter-relationship in glomerular filtration," Human Molecular Genetics, vol. 11, no. 4, pp. 379-388, 2002. 
[78] G. Caridi, R. Bertelli, A. Carrea et al., "Prevalence, genetics, and clinical features of patients carrying podocin mutations in steroid-resistant nonfamilial focal segmental glomerulosclerosis," Journal of the American Society of Nephrology, vol. 12, no. 12, pp. 2742-2746, 2001.

[79] S. M. Karle, B. Uetz, V. Ronner, L. Glaeser, F. Hildebrandt, and A. Fuchshuber, "Novel mutations in NPHS2 detected in both familial and sporadic steroid-resistant nephrotic syndrome," Journal of the American Society of Nephrology, vol. 13, no. 2, pp. 388-393, 2002.

[80] M. P. Winn, "Not all in the family: mutations of podocin in sporadic steroid-resistant nephrotic syndrome," Journal of the American Society of Nephrology, vol. 13, no. 2, pp. 577-579, 2002.

[81] M. Gigante, P. Greco, V. Defazio et al., "Congenital nephrotic syndrome of Finnish type: detection of new nephrin mutations and prenatal diagnosis in an Italian family," Prenatal Diagnosis, vol. 25, no. 5, pp. 407-410, 2005.

[82] S. Bolk, E. G. Puffenberger, J. Hudson, D. H. Morton, and A. Chakravarti, "Elevated frequency and allelic heterogeneity of congenital nephrotic syndrome, Finnish type, in the Old Order Mennonites," American Journal of Human Genetics, vol. 65, no. 6, pp. 1785-1790, 1999.

[83] J. Patrakka, V. Ruotsalainen, P. Reponen et al., "Recurrence of nephrotic syndrome in kidney grafts of patients with congenital nephrotic syndrome of the finnish type," Transplantation, vol. 73, no. 3, pp. 394-403, 2002.

[84] L. Liu, S. C. Doné, J. Khoshnoodi et al., "Defective nephrin trafficking caused by missense mutations in the NPHS1 gene: insight into the mechanisms of congenital nephrotic syndrome," Human Molecular Genetics, vol. 10, no. 23, pp. 2637 2644, 2001.

[85] G. Caridi, R. Bertelli, M. Di Duca et al., "Broadening the spectrum of diseases related to podocin mutations," Journal of the American Society of Nephrology, vol. 14, no. 5, pp. 12781286, 2003.

[86] R. G. Ruf, A. Lichtenberger, S. M. Karle et al., "Patients with mutations in NPHS2 (Podocin) do not respond to standard steroid treatment of nephrotic syndrome," Journal of the American Society of Nephrology, vol. 15, no. 3, pp. 722-732, 2004.

[87] S. Weber, O. Gribouval, E. L. Esquivel et al., "NPHS2 mutation analysis shows genetic heterogeneity of steroid-resistant nephrotic syndrome and low post-transplant recurrence," Kidney International, vol. 66, no. 2, pp. 571-579, 2004.

[88] T. B. Huber, M. Simons, B. Hartleben et al., "Molecular basis of the functional podocin-nephrin complex: mutations in the NPHS2 gene disrupt nephrin targeting to lipid raft microdomains," Human Molecular Genetics, vol. 12, no. 24, pp. 3397-3405, 2003.

[89] M. Schultheiss, R. G. Ruf, B. E. Mucha et al., "No evidence for genotype/phenotype correlation in NPHS1 and NPHS2 mutations," Pediatric Nephrology, vol. 19, no. 12, pp. 13401348, 2004.

[90] G. Caridi, A. Berdeli, M. Dagnino et al., "Infantile steroid-resistant nephrotic syndrome associated with double homozygous mutations of podocin," American Journal of Kidney Diseases, vol. 43, no. 4, pp. 727-732, 2004.

[91] H. Tsukaguchi, A. Sudhakar, T. C. Le et al., "NPHS2 mutations in late-onset focal segmental glomerulosclerosis: R229Q is a common disease-associated allele," Journal of Clinical Investigation, vol. 110, no. 11, pp. 1659-1666, 2002.

[92] A. C. Pereira, A. B. Pereira, G. F. Mota et al., "NPHS2 R229Q functional variant is associated with microalbuminuria in the general population," Kidney International, vol. 65, no. 3, pp. 1026-1030, 2004.

[93] P. Niaudet, "Genetic forms of nephrotic syndrome," Pediatric Nephrology, vol. 19, no. 12, pp. 1313-1318, 2004.

[94] R. G. Ruf, A. Fuchshuber, S. M. Karle et al., "Identification of the first gene locus (SSNS1) for steroid-sensitive nephrotic syndrome on chromosome 2p," Journal of the American Society of Nephrology, vol. 14, no. 7, pp. 1897-1900, 2003.

[95] D. Landau, T. Oved, D. Geiger, L. Abizov, H. Shalev, and R. Parvari, "Familial steroid-sensitive nephrotic syndrome in Southern Israel: clinical and genetic observations," Pediatric Nephrology, vol. 22, no. 5, pp. 661-669, 2007.

[96] R. Habib, "Nephrotic syndrome in the 1st year of life," Pediatric Nephrology, vol. 7, no. 4, pp. 347-353, 1993.

[97] B. Hinkes, R. C. Wiggins, R. Gbadegesin et al., "Positional cloning uncovers mutations in PLCE1 responsible for a nephrotic syndrome variant that may be reversible," Nature Genetics, vol. 38, no. 12, pp. 1397-1405, 2006.

[98] M. Gessler, A. Konig, and G. A. P. Bruns, "The genomic organization and expression of the WT1 gene," Genomics, vol. 12, no. 4, pp. 807-813, 1992.

[99] R. G. Ruf, M. Schultheiss, A. Lichtenberger et al., "Prevalence of WT1 mutations in a large cohort of patients with steroidresistant and steroid-sensitive nephrotic syndrome," Kidney International, vol. 66, no. 2, pp. 564-570, 2004.

[100] B. Mucha, F. Ozaltin, B. G. Hinkes et al., "Mutations in the Wilms' tumor 1 gene cause isolated steroid resistant nephrotic syndrome and occur in exons 8 and 9," Pediatric Research, vol. 59, no. 2, pp. 325-331, 2006.

[101] F. Aucella, L. Bisceglia, P. Bonis et al., "WT1 mutations in nephrotic syndrome revisited. High prevalence in young girls, associations and renal phenotypes," Pediatric Nephrology, vol. 21, no. 10, pp. 1393-1398, 2006.

[102] S. G. Sabnis, T. T. Antonovych, and W. P. Argy, "Nail-patella syndrome," Clinical Nephrology, vol. 14, no. 3, pp. 148-153, 1980.

[103] J. H. Miner, R. Morello, K. L. Andrews et al., "Transcriptional induction of slit diaphragm genes by Lmxlb is required in podocyte differentiation," Journal of Clinical Investigation, vol. 109, no. 8, pp. 1065-1072, 2002.

[104] M. Zenker, T. Tralau, T. Lennert et al., "Congenital nephrosis, mesangial sclerosis, and distinct eye abnormalities with microcoria: an autosomal recessive syndrome," American Journal of Medical Genetics, vol. 130, no. 2, pp. 138-145, 2004.

[105] M. Zenker, T. Aigner, O. Wendler et al., "Human laminin $\beta 2$ deficiency causes congenital nephrosis with mesangial sclerosis and distinct eye abnormalities," Human Molecular Genetics, vol. 13, no. 21, pp. 2625-2632, 2004.

[106] N. Sachs, M. Kreft, M. A. van den Bergh Weerman et al., "Kidney failure in mice lacking the tetraspanin CD151," Journal of Cell Biology, vol. 175, no. 1, pp. 33-39, 2006.

[107] J. M. Clewing, B. C. Antalfy, T. Lücke et al., "Schimke immuno-osseous dysplasia: a clinicopathological correlation," Journal of Medical Genetics, vol. 44, no. 2, pp. 122-130, 2007.

[108] N. Kambham, N. Tanji, R. L. Seigle et al., "Congenital focal segmental glomerulosclerosis associated with $\beta 4$ integrin mutation and epidermolysis bullosa," American Journal of Kidney Diseases, vol. 36, no. 1, pp. 190-196, 2000.

[109] L. Pulkkinen, D. U. Kim, and J. Uitto, "Epidermolysis bullosa with pyloric atresia: novel mutations in the $\beta 4$ integrin gene (ITGB4)," American Journal of Pathology, vol. 152, no. 1, pp. 157-166, 1998.

[110] L. Pulkkinen, V. E. Kimonis, Y. Xu, E. N. Spanou, W. H. I. McLean, and J. Uitto, "Homozygous $\alpha 6$ integrin mutation in 
junctional epidermolysis bullosa with congenital duodenal atresia," Human Molecular Genetics, vol. 6, no. 5, pp. 669674, 1997.

[111] A. Rötig, "Renal disease and mitochondrial genetics," Journal of Nephrology, vol. 16, no. 2, pp. 286-292, 2003.

[112] A. Rötig, E. L. Appelkvist, V. Geromel et al., "Quinoneresponsive multiple respiratory-chain dysfunction due to widespread coenzyme Q10 deficiency," The Lancet, vol. 356, no. 9227, pp. 391-395, 2000.

[113] F. Diomedi-Camassei, S. Di Giandomenico, F. M. Santorelli et al., "COQ2 nephropathy: a newly described inherited mitochondriopathy with primary renal involvement," Journal of the American Society of Nephrology, vol. 18, no. 10, pp. 2773-2780, 2007.

[114] O. Hotta, C. N. Inoue, S. Miyabayashi, T. Furuta, A. Takeuchi, and Y. Taguma, "Clinical and pathologic features of focal segmental glomerulosclerosis with mitochondrial tRNALeu(UUR) gene mutation," Kidney International, vol. 59, no. 4, pp. 1236-1243, 2001.

[115] P. Niaudet, "Mitochondrial disorders and the kidney," Archives of Disease in Childhood, vol. 78, no. 4, pp. 387-390, 1998.

[116] M. Hirano, K. Konishi, N. Arata et al., "Renal complications in a patient with A-to-G mutation of mitochondrial DNA at the 3243 position of leucine tRNA," Internal Medicine, vol. 41, no. 2, pp. 113-118, 2002.

[117] W.-K. Lee and F. Thévenod, "A role for mitochondrial aquaporins in cellular life-and-death decisions?" American Journal of Physiology, vol. 291, no. 2, pp. C195-C202, 2006.

[118] L. Barisoni and J. B. Kopp, "Modulation of podocyte phenotype in collapsing glomerulopathies," Microscopy Research and Technique, vol. 57, no. 4, pp. 254-262, 2002.

[119] M.-L. Solin, S. Pitkänen, J.-W. Taanman, and H. Holthöfer, "Mitochondrial dysfunction in congenital nephrotic syndrome," Laboratory Investigation, vol. 80, no. 8, pp. 12271232, 2000.

[120] H. Holthöfer, M. Kretzler, A. Haltia et al., "Altered gene expression and functions of mitochondria in human nephrotic syndrome," FASEB Journal, vol. 13, no. 3, pp. 523-532, 1999.

[121] D. Calvo, J. Dopazo, and M. A. Vega, "The CD36, CLA1 (CD36L1), and LIMPII (CD36L2) gene family: cellular distribution, chromosomal location, and genetic evolution," Genomics, vol. 25, no. 1, pp. 100-106, 1995.

[122] D. Reczek, M. Schwake, J. Schröder et al., "LIMP-2 Is a Receptor for Lysosomal Mannose-6-Phosphate-Independent Targeting of $\beta$-Glucocerebrosidase," Cell, vol. 131, no. 4, pp. 770-783, 2007.

[123] A. Balreira, P. Gaspar, D. Caiola et al., "A nonsense mutation in the LIMP-2 gene associated with progressive myoclonic epilepsy and nephrotic syndrome," Human Molecular Genetics, vol. 17, no. 14, pp. 2238-2243, 2008.

[124] S. F. Berkovic, L. M. Dibbens, A. Oshlack et al., "Arraybased gene discovery with three unrelated subjects shows SCARB2/LIMP-2 deficiency causes myoclonus epilepsy and glomerulosclerosis," American Journal of Human Genetics, vol. 82, no. 3, pp. 673-684, 2008.

[125] L. M. Dibbens, R. Michelucci, A. Gambardella et al., "SCARB2 mutations in progressive myoclonus epilepsy (PME) without renal failure," Annals of Neurology, vol. 66, no. 4, pp. 532-536, 2009.

[126] W. Kriz, "TRPC6 - a new podocyte gene involved in focal segmental glomerulosclerosis," Trends in Molecular Medicine, vol. 11, no. 12, pp. 527-530, 2005.
[127] E. J. Brown, J. S. Schlöndorff, D. J. Becker et al., "Mutations in the formin gene INF2 cause focal segmental glomerulosclerosis," Nature Genetics, vol. 42, no. 1, pp. 72-76, 2010.

[128] O. Boyer, G. Benoit, O. Gribouval et al., "Mutations in INF2 are a major cause of autosomal dominant focal segmental glomerulosclerosis," Journal of the American Society of Nephrology, vol. 22, no. 2, pp. 239-245, 2011.

[129] J. Faix and R. Grosse, "Staying in shape with formins," Developmental Cell, vol. 10, no. 6, pp. 693-706, 2006.

[130] D. T. Brandt, S. Marion, G. Griffiths, T. Watanabe, K. Kaibuchi, and R. Grosse, "Dial and IQGAP1 interact in cell migration and phagocytic cup formation," Journal of Cell Biology, vol. 178, no. 2, pp. 193-200, 2007.

[131] A. M. Bashour, A. T. Fullerton, M. J. Hart, and G. S. Bloom, "IQGAP1, a Rac- and Cdc42-binding protein, directly binds and cross- links microfilaments," Journal of Cell Biology, vol. 137, no. 7, pp. 1555-1566, 1997.

[132] S. Lehtonen, J. J. Ryan, K. Kudlicka, N. Iino, H. Zhou, and M. G. Farquhar, "Cell junction-associated proteins IQGAP1, MAGI-2, CASK, spectrins, and $\alpha$-actinin are components of the nephrin multiprotein complex," Proceedings of the National Academy of Sciences of the United States of America, vol. 102, no. 28, pp. 9814-9819, 2005.

[133] B. Hinkes, R. C. Wiggins, R. Gbadegesin et al., "Positional cloning uncovers mutations in PLCE1 responsible for a nephrotic syndrome variant that may be reversible," Nature Genetics, vol. 38, no. 12, pp. 1397-1405, 2006.

[134] R. J. Shalhoub, "Pathogenesis of lipoid nephrosis: a disorder of T cell function," The Lancet, vol. 2, no. 7880, pp. 556-560, 1974.

[135] S. Zhang, V. Audard, Q. Fan et al., "Immunopathogenesis of idiopathic nephritic syndrome," Contributions to Nephrology, vol. 169, pp. 94-106, 2011.

[136] K. Yan, K. Nakahara, S. Awa et al., "The increase of memory T cell subsets in children with idiopathic nephrotic syndrome," Nephron, vol. 79, no. 3, pp. 274-278, 1998.

[137] T. J. Neuhaus, V. Shah, R. E. Callard, and T. M. Barratt, "T-lymphocyte activation in steroid-sensitive nephrotic syndrome in childhood," Nephrology Dialysis Transplantation, vol. 10, no. 8, pp. 1348-1352, 1995.

[138] D. Sahali, A. Pawlak, S. Gouvello et al., "Transcriptional and non transcriptional alterations of IKappaBalpha in active minimal change nephrotic syndrome," Journal of the American Society of Nephrology, vol. 12, pp. 1648-1658, 2001.

[139] D. Sahali, A. Pawlak, A. Valanciuté et al., "A novel approach to investigation of the pathogenesis of active minimalchange nephrotic syndrome using subtracted cDNA library screening," Journal of the American Society of Nephrology, vol. 13, no. 5, pp. 1238-1247, 2002.

[140] M. Kamal, A. Pawlak, F. BenMohamed et al., "C-mip interacts with the p85 subunit of PI3 kinase and exerts a dual effect on ERK signaling via the recruitment of Dipl and DAP kinase," FEBS Letters, vol. 584, no. 3, pp. 500-506, 2010. 


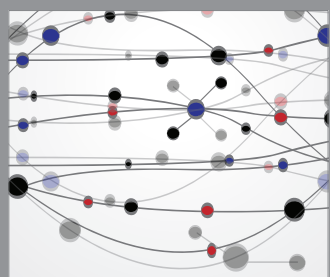

The Scientific World Journal
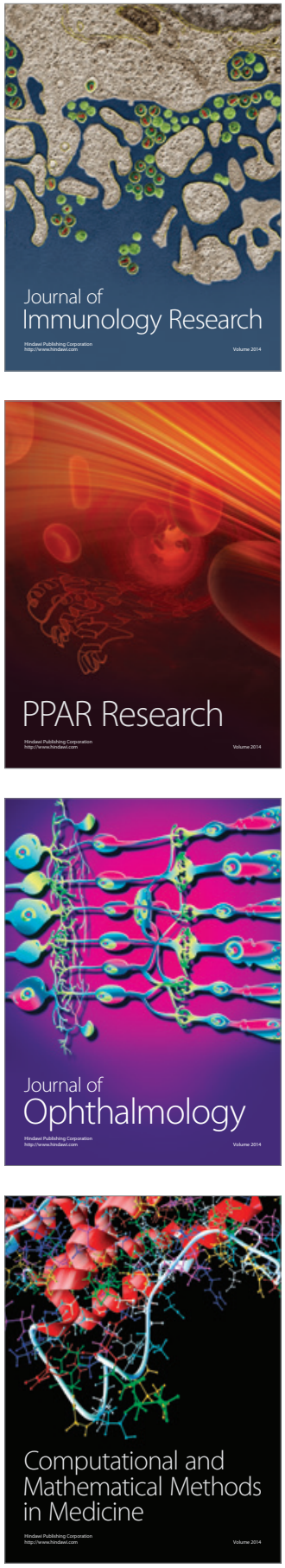

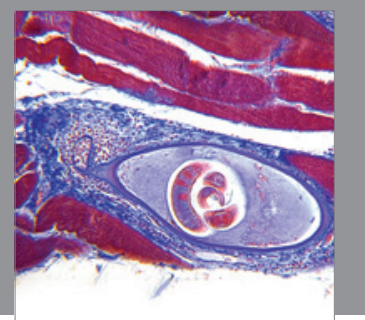

Gastroenterology

Research and Practice
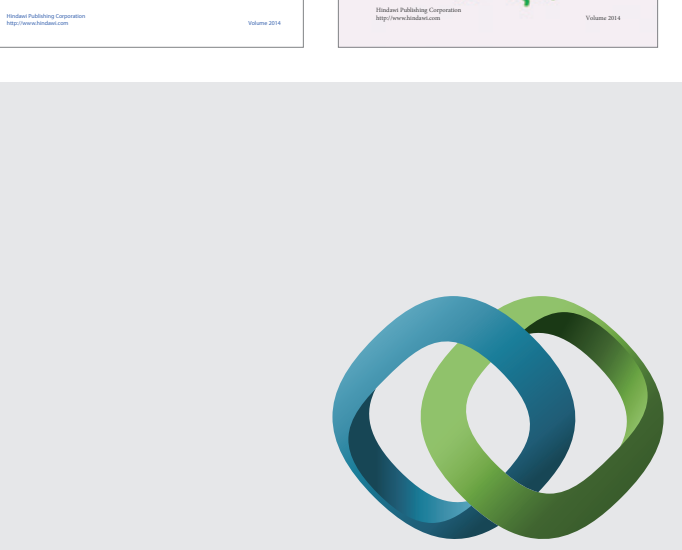

\section{Hindawi}

Submit your manuscripts at

http://www.hindawi.com
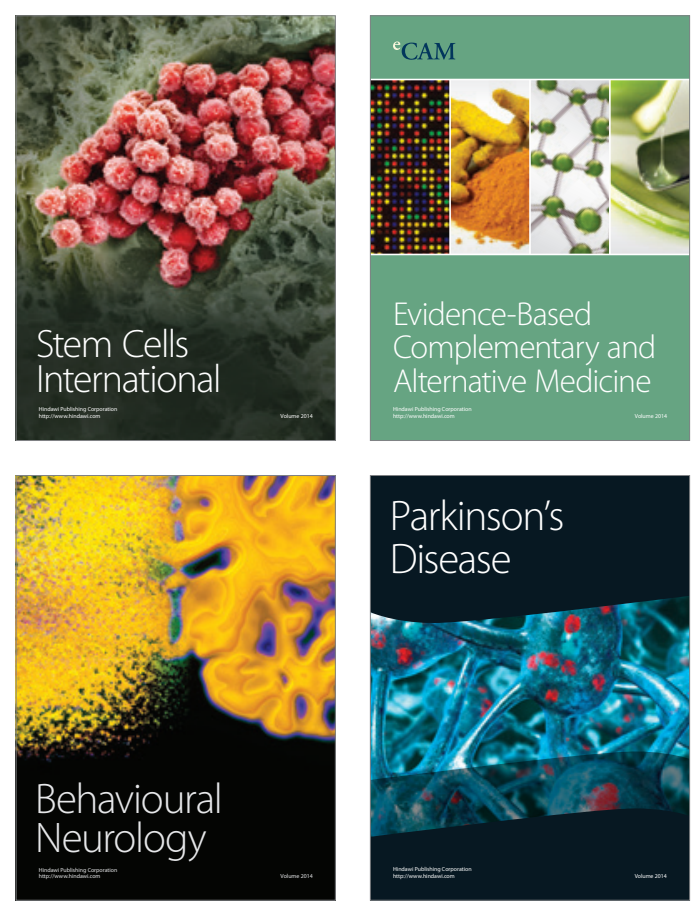

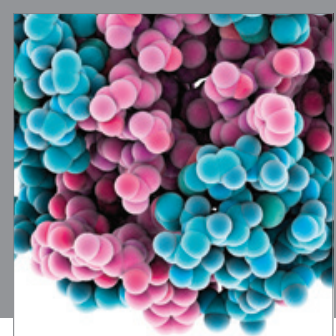

Journal of
Diabetes Research

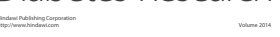

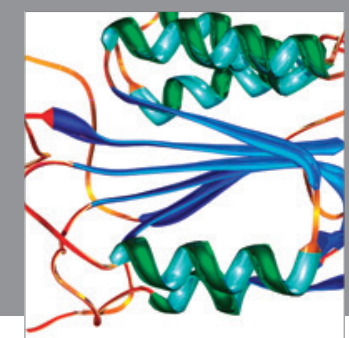

Disease Markers
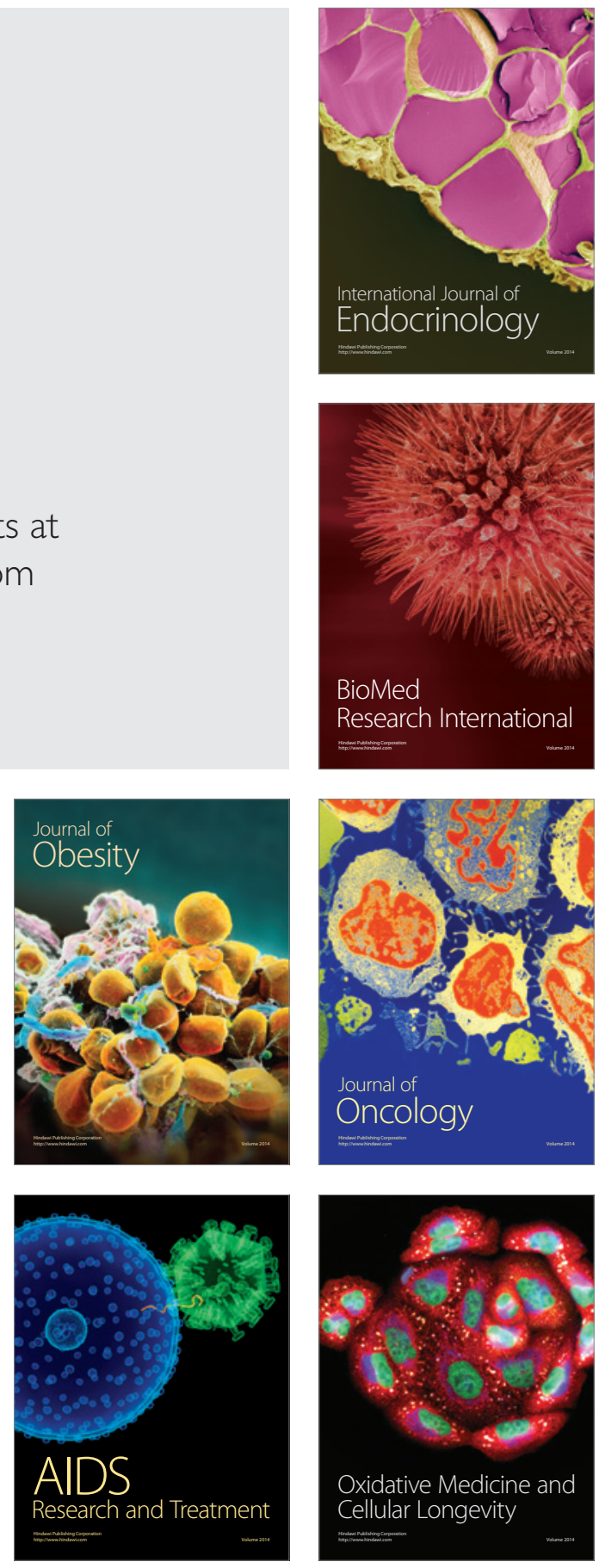